\title{
Effect of Abstinence on Psychological Distress Scores, Social Dysfunction Scores, Total General Health Questionnaire Scores-12, and Total Quality of Life Scores in Men with Methamphetamine Dependence in Therapeutic Community
}

\author{
Thomas Hendriko*, Elmeida Effendy (D), Vita Camellia \\ Department of Psychiatry, Faculty of Medicine, Universitas Sumatera Utara, Medan, Indonesia
}

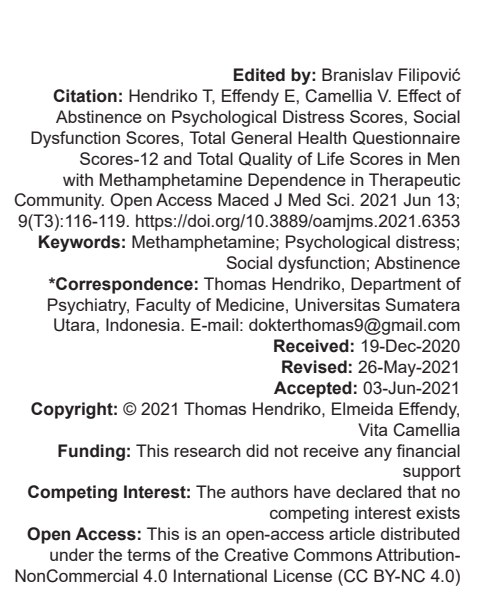

Abstract

AIM: We looked for differences in abstinence influence on Psychological Distress Scores, Social Dysfunction Scores Total General Health Questionnaire - 12 (GHQ-12), and Total Quality of Life Scores on men with Methamphetamine dependence in the Therapeutic Community.

METHODS: This study was conducted a numerical comparative analytical analysis paired with twice measurements with subject retrieval done using consecutive sampling. The participant of this study was 47 subjects who selected by inclusion and exclusion criteria.

RESULTS: Found psychological distress score of the abuser was $p<0.001$, different with social dysfunction score there was no significant difference where the score was $p=0.062$, the total GHQ-12 score was a significant difference where the score was $p=0.025$ while in the total quality of life score (SF-36) there was a significant difference with the score of $p<0.001$.

CONCLUSIONS: After abstinence, quarantine was found to improve attitude, behavior, cognitive, and social function such as appropriate communication and active social relationship with others compared with before abstinence quarantine.

\section{Introduction}

Around the world, physical, psychological, and mental health problems were substance use disorders are often associated with many psychiatric disorders, including depression and anxiety [1].

Methamphetamine (MA) dependence can be related to various mental and emotional disorders. Be that as it may, few researches have efficiently inspected these disorders and conceivable chance variables. The research used structured diagnostic interviews to evaluate the prevalence and comorbidity patterns of mental and emotional disorders in individuals with MA dependence and search the risk factors for this comorbidity [2].

MA is a drug that highly addictive, and in the past few years, its misuse has become more prevail. About $0.3-1.3 \%$ of the world's population has been abuse the amphetamine drug. This rate is also higher in the Middle East. Although the leading cause of death is not drug use disorders, it has an important role in the burden of disability around the world. In 2010 , about $0.8 \%$ of the world's disability-adjusted living years (20.0 million) were directly related to illegal drug dependence [3], [4].

Data obtained from the Data and Information Center from the Ministry of Health of the Republic of Indonesia, it is known that the abuse of narcotics from year to year its prevalence continues to increase. The results of the survey reported by the National Narcotics Agency and the Center for Health Research, University of Indonesia in 2008 obtained a prevalence rate of $1.9 \%$ and in 2011 increased to $2.2 \%$ or approximately 4 million Indonesians aged 10-60 years as narcotic abuse. Data from the United Nations Office on Drugs and Crime in 2011 estimated that $3.6-6.9 \%$ of the world's population aged 15-64 use narcotics at least once a year [5].

Substance dependence is a major health problem, especially at the age of $12-65$ years. The study conducted by Jose, Loraine, and Jacqueline reported about seven out of every ten people aged 12-65 living in Lima, Peru's capital, reported taking illicit drugs in 2010 that $4.8 \%$ of the national population had used illicit drugs in their lives and the users in 2010 increased to 180,700 . The potential addiction to illicit drugs was 
also explained by the study, which showed that 58,556 people had signs of dependence on marijuana, cocaine paste about 33,280 and 23,852 on cocaine. These signs are determined based on the criteria in the International Statistical Classification (ICD-10) [4].

\section{Methods}

\section{Study participants}

Participants of this study were men who entered in Insyaf Social Rehabilitation Center of Narcotic Abuser in North Sumatra, they were diagnosed by substance dependence syndrome using Assessment Smoking and Substance Involvement Screening Test (ASSIST). The inclusion criteria were aged from 15 until 45 years old, who undergoing abstinence program, only MA substance more than one year, from the ASSIST rating scale got score $\geq 27$ and cooperative population. The exclusion criteria were no history of other medical illnesses, organic mental disorders, and other psychiatric disorders according to mini ICD-10 rating scale, the study was conducted from August 2019 to December 2019.

\section{Measurements}

\section{Outcome}

Data retrieval was preceded by screening using inclusion and exclusion criteria. Before entering the therapy program, first carried out urine toxicology rapid test, and who qualified in this study, who positively the only MA who was asked for approval to follow this study. Conducting screening using Mini ICD-10, measuring the level of sustainability using ASSIST using the General Health Questionnaire- 12 (GHQ-12) questionnaire and the SF - 36 quality of life questionnaire with the beginning of a brief explanation of the questionnaire, following abstinence in the Therapeutic Community, then re-examining urine through a rapid test.

\section{Statistical analysis}

This study was an experimental study with pre- and post-design, using categorical comparative analysis of pairs of twice measurements, taking subjects by nonprobability sampling, consecutive sampling. Analysis of the data collected was conducted using the statistical package for service solution. When normally distributed data was performed, data analysis used paired t-tests. If the data were not distributed normally, then the data transformation was carried out using Log, if it remained not distributed normally, then the data analysis was carried out using the Wilcoxon Test. Categorical variables were presented with $n(\%)$, normal distribution numeric variables were presented with the average score \pm of the standard deviation, the numeric variable of the distribution was not normally presented with the median score (minimum-maximum score).

\section{Results}

\section{Characteristic demographic}

From Table 1, the highest education level of the participant was senior high school (57.4\%), with unmarried $(66 \%)$, had variety job $(59.6 \%)$, duration's use between 1 until 10 years.

Table 1: Characteristic demographic

\begin{tabular}{lll}
\hline Variable & Average \pm s.b & $\mathrm{n}(\%)$ \\
\hline Age(years) & $22.60 \pm 4.62$ & \\
Education level & & $5(10.6)$ \\
$\quad$ Elementary Schools & & $10(21.3)$ \\
$\quad$ Junior High Schools & & $27(57.4)$ \\
$\quad$ Senior High Schools & $5(10.6)$ \\
$\quad$ University & & \\
Marital Status & & $16(34)$ \\
$\quad$ Married & & $31(66)$ \\
$\quad$ Not Married & & \\
Job status & & $28(59.6)$ \\
$\quad$ Work & & $19(40.4)$ \\
$\quad$ Not work & & \\
Use duration & & \\
Median( min-max) & $4(1-10)$ & \\
ASSIST & $33.91 \pm 4.10$ & \\
\hline
\end{tabular}

\section{Bivariate analysis}

Table 2 shows the effect of abstinence on psychological distress scores in men with methamphetamine dependence in therapeutic community. They were showing the median score in psychological distress scores in week 0 before abstinence was 12 with a minimum score limit - maximum 10-16 while in week four after abstinence was 12 with a minimum score limit - maximum 8-14. The results of the analysis with the Wilcoxon test for the effect of abstinence on psychological distress scores in week 0 and week 4 had $p<0.001$ scores indicating there was a very significant difference.

Table 3 shows the effect of abstinence on social dysfunction scores, total general health questionnaire-12 score, and total quality of life score in men with methamphetamine dependence in therapeutic communities. The average score on the social dysfunction score in the $0^{\text {th }}$ week before abstinence was 11.02 with a standard deviation of \pm 1.713 , while in the 4 th week after abstinence was 11.64 with a standard deviation of \pm 1.799 . The results of the paired t-test analysis showed no significant differences in the effect of abstinence on social dysfunction scores in week 0 and week 4 with a score of $p=0.062$. In the total score of GHQ-12 in the $0^{\text {th }}$ week before abstinence was 23.64 with a standard deviation of \pm 3.082 , while in the $4^{\text {th }}$ week after abstinence was 22.74 with a standard deviation of \pm 3.025 . The results of the paired t-test analysis showed there was a significant difference in the effect of abstinence on social dysfunction 
scores in week 0 and week 4 with a score of $p=0.025$ while in the total quality of life scores in week 0 before abstinence 22.83 with a standard deviation of \pm 1.629 while in the 4th week after abstinence was 19.98 with a standard deviation of \pm 2.480 . The results of the paired t-test analysis showed that there was a very significant difference in the effect of abstinence on social dysfunction scores in week 0 and week 4 with a $p<0.001$ scores.

Table 2: Effect of abstinence on psychological distress scores in men with methamphetamine dependence in therapeutic community

\begin{tabular}{llll}
\hline $\begin{array}{l}\text { Effect of abstinence on } \\
\text { psychological distress scores }\end{array}$ & $\mathrm{n}$ & Median(minimum-maximum ) & p-score \\
\hline 0 weeks & 47 & $12(10-16)$ & $<0.001$ \\
4 weeks & 47 & $12(8-14)$ & \\
\hline *Wilcoxon Test. & & &
\end{tabular}

\section{Discussion}

MA known as "shisheh" in Iran is a widely used drug in many parts of the world and nearly a decade is available to most drug users and has considerable use [6], [7], [8]. MA provides its behavioral effects by altering the use of monoamines as neuron signals in the brain, especially in catecholamine neurons in reward pathways and executive functions of the brain. It increased dopaminergic activity in the mesolimbic pathway. The effects of MA that stimulate euphoria and locomotors depend on the size and speed of increased concentrations of synaptic dopamine and norepinephrine in the striatum and short-term effects of MA including euphoria, alertness, wakefulness, increased confidence, hyperactivity, and loss of appetite [8], [9].

Table 3: Effect of abstinence on social dysfunction scores, total general health questionnaire-12 score, and total quality of life score in men with methamphetamine dependence in therapeutic communities

\begin{tabular}{lcccc}
\hline $\begin{array}{l}\text { Effect of abstinence on social } \\
\text { dysfunction scores }\end{array}$ & $\mathrm{n}$ & Average $\pm \mathrm{sb}$ & $\mathrm{Cl} 95 \%$ & $\mathrm{p}$-score \\
\hline $\mathbf{0}$ weeks & 47 & $11.02 \pm 1.713$ & $-1.267-0.032$ & 0.062 \\
$\quad 4$ weeks & 47 & $11.64 \pm 1.799$ & & \\
On the total score of GHQ-12 & & & & \\
$\quad$ ( weeks & 47 & $23.64 \pm 3.082$ & $0.119-1.669$ & $0.025^{*}$ \\
$\quad 4$ weeks & 47 & $22.74 \pm 3.025$ & & \\
On the total score of life quality & & & & $<0.001^{*}$ \\
$\quad$ weeks & 47 & $22.83 \pm 1.629$ & $2.09-3.58$ & \\
$\quad 4$ weeks & 47 & $19.98 \pm 2.480$ & & \\
\hline Paired t-test. & & & &
\end{tabular}

MA using possibly associated to alteration of psychological and social function. But there was still lack of general information about potential psychosocial behaviors and relationship, psychological distress, and in particular regarding factors potentially mediating the relationship between socio-demographic characteristics and mental health, for example, stressful experiences or family functions. Hence, while family type and marital status have been reported to be relevant, the quality of family relationships may be the same or even more important [1].

The results of the study obtained on the influence of abstinence on psychological stress, the total score of $\mathrm{GHQ}-12$ and quality of life score are, there were significant differences according to the study conducted by Bishal et al. [1], Mariam et al. [3], Garcia et al. [10], and Masri et al. [11]. This was because dopamine was released, so it was responsible for the effects of euphoria, but long-term use of MA caused molecular changes in the dopamine system and contributes to damage to nerve terminals in the brain and caused motor disorders, a rapid decrease in cognitive ability, increased anxiety [4], [8].

Community therapeutics is an intensive and comprehensive care model developed for use by adults that have been used to treat adolescent health disorders. The therapeutic community for addiction treatment originated in 1958, when other systems of therapy, such as psychiatry and general medicine, failed to treat alcohol or drug use disorders. The first Therapeutic Community for drug users (Synanon) was founded in California by Chuck Dederich, one of the earliest members of Alcoholics Anonymous (AA), who wanted to provide a controlled (substance-free) environment in which alcohol and substance users could rebuild lives, using the principle AA principles along with social learning models [12].

In social dysfunction scores on the influence of abstinence with the dependence of MA substances, there was no significant difference in the effect of abstinence on social dysfunction scores. In contrast to studies conducted by Garcia et al. [10] in which this study showed significant differences, this was due to several factors that have the potential to mediate the relationship between sociodemographic characteristics and mental health, such as stress experiences or family factors. Other factors may be relevant to socio-cultural contact [1].

\section{Conclusion}

This study can be used as a reference to compare the dependence on not just one type of substance but several types of substances. It is expected that clinicians and related parties pay attention to psychosocial interventions to prevent the occurrence of MA dependence. It is recommended to have a psychiatrist to determine the follow-up related to the high psychological distress of substance use. This study requires monitoring of psychological distress before and after abstinence in men with substance dependence and requires collaboration between psychiatrists and clinical psychologists for further treatment.

\section{References}

1. Gyawali B, Choulagai BP, Paneru DP, Ahmad M, Leppin A Kallestrup P. Prevalence and correlates of psychological distress symptoms among patients with substance use disorders in drug rehabilitation centers in urban Nepal: A cros-sectional study. BMC Psychiatry. 2016;16(1):314. https://doi.org/10.1186/ 


\section{s12888-016-1003-6 \\ PMid:27609330}

2. Akindipe T, Wilson D, Stein DJ. Psychiatric disorders in individuals with methamphetamine dependence: Prevalence and risk factors. Metab Brain Dis. 2014;29(2):351-7. https://doi. org/10.1007/s11011-014-9496-5

PMid:24532047

3. Bagheri M, Mokri A, Khosravi A, Kabir K. Effect of abstinence on depression, anxiety, and quality of life in chronic methamphetamine users in a therapeutic community. Int J High Risk Behav Addict. 2015;4(3):e23903. https://doi.org/10.5812/ ijhrba.23903

PMid:26495258

4. Díaz JE, Gaino LV, de Souza J. Clinical and socio-demographic characteristics of patients at a rehabilitation center for chemical dependency. Rev Gaucha Enferm. 2016;37(2):e57037.

PMid:27410673

5. Kementerian Kesehatan Republik Indonesia, Pusat Data dan Informasi; 2014.

6. Seyed RR, Richard AR. Current research on methamphetamine: Epidemiology, medical and psychiatric effects, treatment, and harm reduction efforts. Addict Health. 2014;6(3-4):146-54. PMid:25984282

7. Sadock BJ, Sadock VA, Ruis P. Substance use and addictive disorders. In: Kaplan and Sadock's Synopsis of Psychiatry Behavioral Science/Clinical Psychiatry. $11^{\text {th }}$ ed. Philadelphia,
PA: Lippincott Williams \& Wilkins; 2015. p. 1444-64.

8. David JH, Sharon LS, Jane G, David JN. Amphetamine, past and present-a pharmacological and clinical perspective. J Psychopharmacol. 2013;27(6):479-96.

PMid:23539642

9. Departemen Kesehatan Republik Indonesia. Pedoman Penggolongan dan Diagnosis Gangguan Jiwa di Indonesia III (PPDGJ-III). Departemen Kesehatan Republik Indonesia: Jakarta; 1993. p. 87-95. https://doi.org/10.6066/ jtip.2013.24.2.121

10. Verdejo-García A, Bechara A, Recknor EC, Pérez-García M Executive dysfunction in substance dependent individuals during drug use and abstinence: An examination of the behavioral, cognitive and emotional correlates of addiction. J Int Neuropsychol Soc. 2006;12(3):405-15. https://doi.org/10.1017/ s1355617706060486 PMid:16903133

11. Masri $\mathrm{R}$, Kadhum $\mathrm{M}$, Farrell $\mathrm{SM}$, Khamees A, Al-Taiar $\mathrm{H}$ Molodynski A. Wellbeing and mental health amongst medical students in Jordan: A descriptive study. Int Rev Psychiatry. 2019;31(7-8):619-25. https://doi.org/10.1080/09540261.2019.1 670402

PMid:31578112

12. Kementrian Sosial RI. Pedoman Pelaksanaan Rehabilitas Sosial Korban Penyalahgunaan NAPZA; Balai Rehabilitasi Sosial Korban Penyalahgunaan NAPZA "INSYAF" Medan Sumatera Utara; 2018. https://doi.org/10.33007/ska.v9i1.1767 